Seção Temática: Balanço do Fundeb

Volume 11 - $2021 \mid$ n. 14

\title{
As Esperanças Perdidas da Educação de Jovens e Adultos com o Fundeb ${ }^{1}$
}

\author{
José Marcelino de Rezende Pinto \\ Universidade de São Paulo (USP), São Paulo/SP - Brasil
}

\section{Resumo}

O artigo analisa a evolução de indicadores de atendimento de EJA em diálogo com as expectativas geradas pela implantação do Fundo de Manutenção e Desenvolvimento da Educação Básica e de Valorização dos Profissionais da Educação (Fundeb), que passou a contabilizar as matrículas dessa modalidade para efeito de repasse dos recursos aos entes federados. Trata-se de uma análise documental tendo por base os dados de matrícula do Censo Escolar, sistematizados em séries históricas pelo Laboratório de Dados Educacionais (LDE) da UFPR, bem como o monitoramento dos indicadores de cumprimento das metas do Plano Nacional de Educação (PNE) realizado pelo INEP. Também é feita uma estimativa dos recursos propiciados à EJA pelo governo federal e pelos estados e municípios. Os dados indicam uma queda sistemática nas matrículas de EJA no período de 2007 a 2019 e uma lenta progressão rumo às metas do PNE mais diretamente associadas à modalidade, indicando que dificilmente elas serão atingidas em 2024. Os recursos federais destinados para a subfunção EJA saem de um patamar de R\$ 1,8 bilhões, empenhados em 2012, para míseros $R \$ 8$ milhões, em 2020, queda de 95,56\%. Já no caso dos estados, DF e municípios estimou-se, com base em modelo referenciado na participação das matrículas, recursos da ordem de $0,28 \%$ do PIB, em 2019. Finalmente analisam-se eventuais efeitos do novo Fundeb e sugerem-se algumas medidas para a garantia do direito à educação básica aos jovens e adultos brasileiros.

Palavras-chave: Educação de Jovens e Adultos (EJA). Fundeb. Financiamento da educação. Financiamento da EJA.

\section{The Lost Hopes of Youth and Adult Education with Fundeb}

\section{Abstract}

The article analyzes the evolution of YAE service indicators in dialogue with the expectations generated by the implementation of the Fund for the Maintenance and Development of Basic Education and the Valorization of Education Professionals (Fundeb), which started to account for enrollments in this modality for the purpose of transfer of funds to federated entities. This is a documentary analysis based on the enrollment data from the School Census, systematized in historical series by the Universidade Federal do Paraná (UFPR) Educational Data Laboratory (LDE), as well as the monitoring of the indicators of achievement of the goals of the Plano Nacional de Educação (PNE) carried out by INEP. An estimate is also made of the resources provided to YAE by the federal government and by the states and cities. The data indicate a systematic drop in YAE enrollments in the period from 2007 to 2019 and a slow progression towards the goals of the PNE most directly associated with the modality, indicating that they will hardly be reached in 2024. Federal funds earmarked for the YAE subfunction fall from a level of $R \$$ 1.8 billion committed, in 2012 , to a measly $\mathrm{R} \$ 8$ million, in 2020 , a drop of $95.56 \%$. In the case of states, Federal District and cities, resources estimated at $0.28 \%$ of GDP in 2019 were based on a model referenced to participation in enrollments. Finally, possible effects of the new Fundeb are analyzed and some measures are suggested to guarantee the right to basic education for Brazilian youth and adults.

Keywords: Youth and Adult Education (YAE). Fundeb. Education Financing. YAE Financing.

1 Este artigo apresenta parte dos resultados do projeto de pesquisa financiado pelo CNPq (Proc. 409861/2016-2). 
As Esperanças Perdidas da Educação de Jovens e Adultos com o Fundeb

\section{Introdução}

A Constituição Federal de 1988, ao estabelecer em seu art. 208, inciso I, o dever do Estado com o "ensino fundamental obrigatório e gratuito, assegurada, inclusive, sua oferta gratuita para todos a que ele não tiverem acesso na idade própria", representou um grande alento para a Educação de Jovens e Adultos (EJA) no Brasil, honrando a memória de Paulo Freire. No mesmo sentido, a Lei de Diretrizes e Bases da Educação Nacional (LDB), aprovada em 1996, ao criar uma seção para a EJA, indo além dos conceitos de ensino supletivo e campanhas de alfabetização, também trouxe motivos para otimismo, não obstante sua timidez ante o substitutivo Jorge Hage, aprovado pela Comissão de Educação da Câmara, em 1991, bem como o retrocesso representado pela redução da idade para a realização dos exames supletivos (art. 38), frente à lei anterior, um claro estímulo à desescolarização de jovens e adultos (BRASIL, 2008).

De qualquer forma, a confirmação de que a EJA não era prioridade política no governo de Fernando Henrique Cardoso (FHC) veio com o veto à contabilização das matrículas da modalidade de EJA no ensino fundamental, no Fundo de Manutenção e Desenvolvimento do Ensino e de Valorização dos Profissionais do Magistério (Fundef), criado em 1996. Vale a pena lembrar trechos do veto presidencial para ressaltar o peso da agenda neoliberal naquele governo:

Considerar as matrículas do ensino fundamental supletivo, para efeito de distribuição dos recursos do Fundo, é um critério que, embora factível do ponto de vista socioeducacional, na medida em que abraça o universo de alunos que não tiverem a oportunidade de frequentar o ensino regular, é temerário do ponto de vista da precisa repartição dos recursos, pelos aspectos que passamos a expor.

a) A garantia de contabilização do alunado do ensino supletivo, para efeito de recebimento dos recursos, poderá provocar, no âmbito dos governos estaduais e/ou municipais, uma indesejável corrida no sentido de se criar cursos dessa natureza, sem rigor nem a observância dos critérios técnicos-pedagógicos requeridos ao respectivo governo, em detrimento da qualidade, do ensino e, por conseguinte, da adequada formação dos educandos.

b) O MEC não dispõe de dados estatísticos consistentes que possam assegurar uma correta e fidedigna contabilização do alunado do ensino supletivo.

c) O recenseamento do ensino supletivo, em razão da dificuldade de aferição dos dados, pela especificidade da forma de controle e frequência do alunado, baseia-se, via de regra, apenas no registro disponível dos estabelecimentos que ministram essa modalidade de ensino, prejudicando eventuais confirmações da presença, ou mesmo da existência do aluno (BRASIL, 1996).

Ou seja, o que o Executivo temia era uma ampliação das matrículas da EJA, o que representaria um aumento da contribuição do governo federal ao Fundef, fato que o governo FHC queria evitar. Curiosamente, o veto mencionava que os alunos da EJA poderiam receber recursos do Fundef, desde que não fossem contabilizados. Ou seja, para garantir um direito do cidadão e dever do Estado previsto na CF, governadores e prefeitos deveriam buscar recursos adicionais, como se já não tivessem obrigações com o ensino médio e educação infantil, também excluídos do Fundef, ou compartilhar os já parcos recursos do Fundef com o total de alunos do ensino fundamental. Como se sabe, o veto acabou levando vários estados e municípios a adulterarem seus dados do Censo Escolar, contabilizando alunos de EJA 
As Esperanças Perdidas da Educação de Jovens e Adultos com o Fundeb

(faixas etárias acima da considerada típica para o ensino fundamental) como alunos "regulares"2 (PINTO, 2002).

Outra consequência, essa mais positiva, do veto foi levar a sociedade civil a se mobilizar para a sua derrubada, fato que induziu o governo FHC a lançar, em 2001, o programa Recomeço (Resolução FNDE no 12/2001), que destinava recursos adicionais, por fora do Fundef, de $\mathrm{R} \$ 230$ por aluno-ano, para as redes estaduais e municipais em função das matrículas na EJA, com alguns condicionantes (BORGES; JESUS, 2013). Embora inferior ao já ínfimo valor mínimo do Fundef, esse valor correspondia a $63 \%$ do valor base definido para os anos iniciais do ensino fundamental no mesmo ano.

Com o governo de Luiz Inácio Lula da Silva (Lula), iniciado em 2003, esperava-se a derrubada dos vários vetos de FHC ao Fundef. Não foi, contudo, o que ocorreu, havendo apenas uma mudança do nome do programa, que passou a se chamar Fazendo Escola (Resolução FNDE $n^{\circ}$ 5/2003), mantendo os mesmos R\$ 230 por aluno, valor inalterado até 2006, quando representava apenas $34 \%$ do valor mínimo do Fundef para os anos iniciais do ensino fundamental urbano (RUMMERT; VENTURA, 2007; BRASIL, 2008). Cabe ressaltar, contudo, que, enquanto o programa Recomeço estava focalizado apenas em nove estados e apenas $10 \%$ dos municípios com baixo IDH, o Fazendo Escola atingiu todos os estados e municípios.

Não obstante as medidas tímidas do governo FHC, e contrariando as expectativas, como mostra o Gráfico 1, no período do Fundef houve um aumento robusto das matrículas de EJA na rede pública.

GRÁFICO 1- EVOLUÇÃO DAS MATRÍCULAS DE EJA 1995-2007

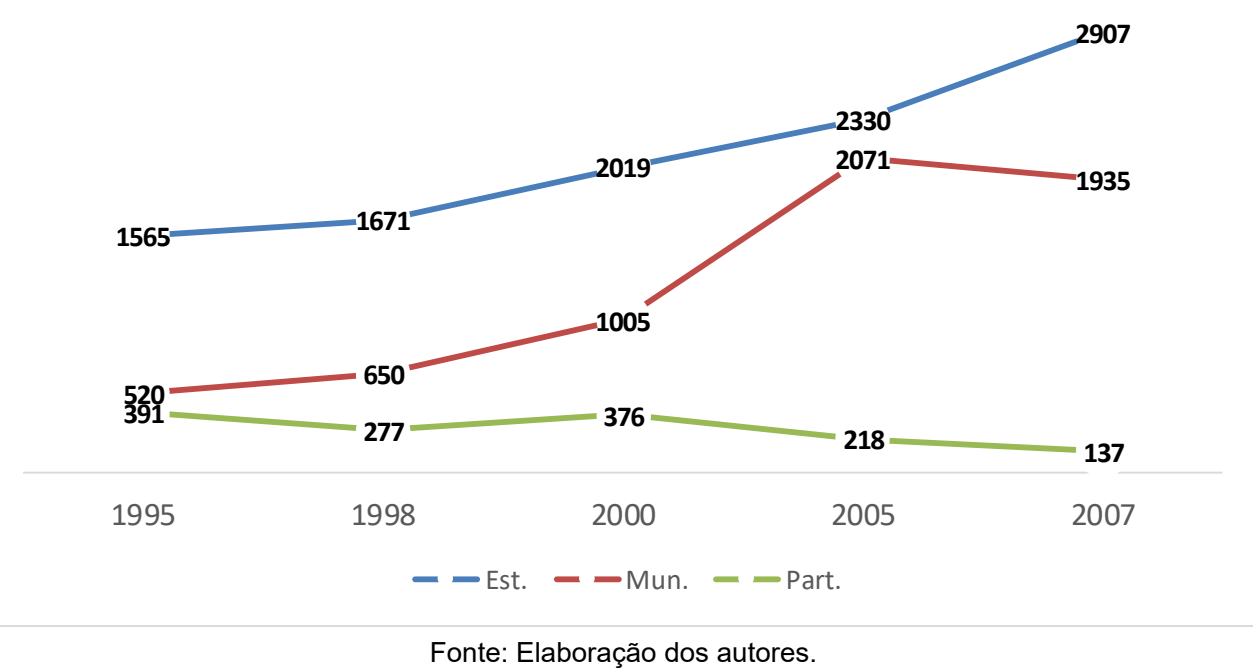

Os dados do Gráfico 1 indicam um crescimento de $74 \%$ nas matrículas em EJA na rede estadual entre o primeiro ano do Fundef de forma compulsória (1998) e o primeiro do Fundeb (2007), e de impressionantes 198\% na rede municipal, chegando a 219\% entre 1998 e 2005, indicando uma queda entre 2005 e 2007 . Por sua vez, a rede privada mostra uma queda de

2 Usa-se a expressão 'regulares' entre aspas, pois os alunos da EJA também o são, mas essa tem sido a forma mais utilizada na literatura. 
$51 \%$ entre 1998 e 2007, indicando que o setor ocupava um nicho de mercado decorrente da falta de oferta pública. Com a expansão desta última, a rede privada tende a encolher. Observa-se ainda um aumento da participação municipal nas matrículas, saindo de $28 \%$, em 1998, para $40 \%$, em 2007, lembrando que, no gráfico, são consideradas todas as etapas de ensino. Esse processo de municipalização foi um dos grandes efeitos do Fundef e se refletiu também na EJA (DI PIERRO, 2014; PINTO, 2018).

Considerando essa expansão, até certo ponto surpreendente, no período do Fundef, mesmo com o veto de $\mathrm{FHC}$, foi com grande entusiasmo que a comunidade educacional recebeu a aprovação, em 2006, do Fundo de Manutenção e Desenvolvimento da Educação Básica e de Valorização dos Profissionais da Educação (Fundeb) com a contabilização de todas as etapas e modalidades da educação básica. Começaria o momento de redenção da EJA?

Uma análise da regulamentação do novo fundo, contudo, já trazia alguns elementos de preocupação. O primeiro deles, encontra-se no art. 11 da Lei $n^{0} 11.496 / 2007$, e estabelece que os recursos destinados à EJA terão como limite até $15 \%$ do total de cada fundo estadual, do DF e/ou municipal. Ou seja, é o mesmo temor da área econômica da explosão das matrículas em EJA, já presentes no veto de FHC no Fundef. O segundo alerta veio com a definição de um fator de ponderação de apenas 0,7 para cada matrícula de EJA, na comparação com as matrículas dos anos iniciais do ensino fundamental urbano. Cabe ressaltar que esses fatores de ponderação não se basearam em qualquer estudo de custo e não encontram justificativa racional, a não ser como mecanismo de desestímulo à modalidade. Posteriormente, esse fator foi ampliado para 0,8, em 2009, estabilizando nesse patamar desde então. Neste mesmo ano foi criada uma nova modalidade de EJA, integrada à educação profissional de nível médio, com fator 1,0 , passando para 1,2, em 2011, não sofrendo novas mudanças, ainda inferior ao fator 1,3 para o ensino médio integrado à educação profissional.

É fácil entender por que não procede essa distinção entre a EJA e o chamado ensino "regular", afinal os professores são os mesmos e a razão de alunos por turma, elemento central no custo-aluno, não a justifica. Levantamento feito na base de dados do Censo Escolar no Laboratório de Dados Educacionais (LDE, 2020) da Universidade Federal do Paraná (UFPR), que será a fonte de todos os dados usados neste artigo, para vários anos, indica que é praticamente a mesma razão aluno/turma no ensino médio, e ela chega a ser inferior no ensino fundamental, mostrando, inclusive, que esse fator deveria ser superior a 1 nessa etapa, como apontado na versão mais recente do Custo Aluno Qualidade inicial (CAQi) (CAMPANHA..., 2018). Na versão original do CAQi não havia diferença entre os fatores de cada etapa da EJA e o chamado ensino regular (CARREIRA; PINTO, 2007).

No item seguinte será analisada a dinâmica do atendimento no período. 
As Esperanças Perdidas da Educação de Jovens e Adultos com o Fundeb

\section{$O$ atendimento da EJA}

A Tabela 1 apresenta a evolução da matrícula da EJA no ensino fundamental de 2007 a 2019, em ordem decrescente de queda.

Tabela 1 - Evolução da matrícula de EJA no ensino fundamental por UF 2007-2019

\begin{tabular}{|c|c|c|c|c|c|c|}
\hline & 2007 & 2010 & 2013 & 2016 & 2019 & $2019 / 2007$ \\
\hline TO & 22.496 & 12.043 & 10.866 & 7.601 & 7.542 & $34 \%$ \\
\hline RO & 42.815 & 44.295 & 37.979 & 25.738 & 15.851 & $37 \%$ \\
\hline $\mathrm{RR}$ & 8.268 & 6.202 & 4.242 & 3.666 & 3.070 & $37 \%$ \\
\hline SP & 456.451 & 310.028 & 228.369 & 207.405 & 176.266 & $39 \%$ \\
\hline MS & 45.075 & 28.460 & 20.060 & 21.437 & 17.842 & $40 \%$ \\
\hline SC & 69.531 & 51.005 & 33.628 & 31.687 & 32.263 & $46 \%$ \\
\hline RJ & 265.280 & 264.426 & 162.530 & 129.290 & 123.956 & $47 \%$ \\
\hline$P A$ & 236.823 & 217.261 & 189.911 & 139.663 & 113.384 & $48 \%$ \\
\hline $\mathrm{RN}$ & 98.357 & 76.214 & 69.418 & 49.951 & 48.718 & $50 \%$ \\
\hline MG & 233.268 & 216.297 & 188.039 & 160.538 & 115.550 & $50 \%$ \\
\hline CE & 201.038 & 138.685 & 121.841 & 96.747 & 101.014 & $50 \%$ \\
\hline$P E$ & 242.273 & 220.053 & 158.050 & 125.699 & 123.665 & $51 \%$ \\
\hline SE & 57.169 & 42.186 & 39.785 & 28.846 & 32.693 & $57 \%$ \\
\hline $\mathrm{BA}$ & 381.441 & 335.096 & 301.626 & 227.892 & 223.951 & $59 \%$ \\
\hline AM & 86.232 & 69.858 & 70.734 & 62.911 & 51.951 & $60 \%$ \\
\hline $\mathrm{GO}$ & 51.710 & 45.564 & 37.257 & 32.418 & 31.432 & $61 \%$ \\
\hline MT & 59.621 & 65.408 & 54.401 & 36.263 & 37.026 & $62 \%$ \\
\hline $\mathrm{RS}$ & 116.294 & 100.241 & 94.369 & 87.521 & 75.322 & $65 \%$ \\
\hline AP & 18.495 & 17.723 & 16.396 & 14.391 & 12.710 & $69 \%$ \\
\hline MA & 191.323 & 167.615 & 150.811 & 111.667 & 133.046 & $70 \%$ \\
\hline PB & 116.281 & 103.998 & 114.209 & 89.419 & 82.619 & $71 \%$ \\
\hline$A C$ & 22.445 & 16.945 & 20.091 & 16.100 & 16.758 & $75 \%$ \\
\hline DF & 34.176 & 27.996 & 27.476 & 27.135 & 25.681 & $75 \%$ \\
\hline PR & 128.317 & 91.827 & 95.564 & 93.539 & 106.617 & $83 \%$ \\
\hline ES & 35.391 & 41.543 & 42.363 & 35.449 & 32.255 & $91 \%$ \\
\hline $\mathrm{PI}$ & 100.886 & 85.341 & 65.581 & 99.087 & 92.565 & $92 \%$ \\
\hline$\overline{\mathrm{AL}}$ & 93.732 & 86.899 & 84.555 & 81.563 & 92.037 & $98 \%$ \\
\hline Total & 3.415 .188 & 2.883 .209 & 2.440 .151 & 2.043 .623 & 1.925 .784 & $56 \%$ \\
\hline
\end{tabular}

Fonte: Censo Escolar do INEP a partir do LDE.

Os dados da Tabela 1 indicam que, ao contrário das expectativas, houve uma queda para praticamente a metade das matrículas de EJA no ensino fundamental, mesmo envolvendo o transcurso de dois planos nacionais de educação (PNE 2001-2011 e PNE 2014- 
As Esperanças Perdidas da Educação de Jovens e Adultos com o Fundeb

2024), ambos com metas de ampliação significativa para a modalidade. Em 11 unidades da federação (UFs), essa queda foi igual ou acima de $50 \%$, chegando a $60 \%$ ou mais em cinco (TO, RO, RR, SP e MS). Em nenhuma unidade federada a matrícula cresceu no período de vigência do Fundeb.

A Tabela 2 apresenta a mesma análise para as matrículas de EJA no ensino médio.

Tabela 2 - Evolução da matrícula de EJA no ensino médio por UF 2007-2019

\begin{tabular}{|c|c|c|c|c|c|c|}
\hline & 2007 & 2010 & 2013 & 2016 & \multicolumn{2}{|c|}{$20192019 / 2007$} \\
\hline MS & 32.269 & 23.309 & 20.333 & 22.509 & 15.314 & $47 \%$ \\
\hline SP & 478.969 & 302.980 & 237.271 & 249.914 & 240.153 & $50 \%$ \\
\hline SC & 67.162 & 55.222 & 42.614 & 41.344 & 36.182 & $54 \%$ \\
\hline $\mathrm{RO}$ & 30.353 & 33.489 & 27.225 & 25.490 & 18.448 & $61 \%$ \\
\hline $\mathrm{RR}$ & 8.694 & 6.686 & 5.217 & 5.952 & 5.503 & $63 \%$ \\
\hline $\mathrm{BA}$ & 137.982 & 109.055 & 114.907 & 96.985 & 96.390 & $70 \%$ \\
\hline DF & 28.545 & 26.588 & 22.888 & 25.696 & 20.316 & $71 \%$ \\
\hline PR & 84.188 & 70.504 & 54.443 & 57.210 & 65.348 & $78 \%$ \\
\hline SE & 13.838 & 12.770 & 12.064 & 10.258 & 11.063 & $80 \%$ \\
\hline$A C$ & 11.291 & 7.812 & 7.095 & 8.103 & 9.160 & $81 \%$ \\
\hline TO & 10.281 & 11.412 & 10.795 & 9.999 & 8.398 & $82 \%$ \\
\hline RS & 73.378 & 56.973 & 55.779 & 68.187 & 60.159 & $82 \%$ \\
\hline RJ & 143.059 & 159.938 & 107.676 & 113.639 & 128.012 & $89 \%$ \\
\hline GO & 41.479 & 35.006 & 25.527 & 26.872 & 37.208 & $90 \%$ \\
\hline CE & 71.270 & 42.869 & 53.250 & 61.560 & 64.573 & $91 \%$ \\
\hline ES & 33.166 & 28.348 & 29.789 & 28.870 & 30.086 & $91 \%$ \\
\hline PB & 32.232 & 36.336 & 32.573 & 32.537 & 29.653 & $92 \%$ \\
\hline MG & 137.171 & 152.558 & 160.386 & 185.538 & 134.267 & $98 \%$ \\
\hline AM & 20.204 & 20.861 & 24.369 & 23.829 & 21.530 & $107 \%$ \\
\hline MT & 32.941 & 37.195 & 43.907 & 33.908 & 37.109 & $113 \%$ \\
\hline PA & 35.717 & 51.183 & 57.049 & 55.408 & 51.831 & $145 \%$ \\
\hline MA & 21.008 & 29.207 & 30.432 & 27.318 & 30.987 & $148 \%$ \\
\hline $\mathrm{AP}$ & 5.118 & 6.001 & 6.374 & 8.942 & 8.064 & $158 \%$ \\
\hline $\mathrm{RN}$ & 9.933 & 15.128 & 16.812 & 17.195 & 17.424 & $175 \%$ \\
\hline PE & 31.430 & 27.891 & 47.126 & 54.585 & 61.947 & $197 \%$ \\
\hline $\mathrm{AL}$ & 8.690 & 11.454 & 14.361 & 21.659 & 24.517 & $282 \%$ \\
\hline $\mathrm{PI}$ & 9.071 & 18.442 & 23.786 & 28.630 & 30.850 & $340 \%$ \\
\hline total & 1.609 .439 & 1.389 .217 & 1.284 .048 & 1.342 .137 & 1.294 .492 & $80 \%$ \\
\hline
\end{tabular}

Fonte: Censo Escolar do INEP a partir do LDE.

Inicialmente, há que se ressaltar os desafios gigantescos colocados para o ensino médio da EJA, considerando que, segundo o IBGE, em 2018, 53\% da população com 25 anos ou 
As Esperanças Perdidas da Educação de Jovens e Adultos com o Fundeb

mais não tinham concluído essa etapa. Segundo os dados da Tabela 2, para o Brasil, houve uma queda constante no período, atingindo um decréscimo de $20 \%$ entre 2007 e 2019. Entre as UFs, contudo, houve comportamentos bastante variados. Assim, em 19 unidades houve queda (para cerca da metade em MS, SP e SC), enquanto em nove outras, houve crescimento, chegando a dobrar em Pernambuco e triplicar em Alagoas (2,8 vezes) e Piauí (3,4 vezes). É positivo o fato de os maiores crescimentos ocorrerem em estados das regiões Norte e Nordeste, ondes os desafios para a modalidade são mais significativos, como se verá adiante.

É interessante também avaliar como se deu a evolução das matrículas de EJA, nas diferentes etapas, entre as dependências administrativas. Os dados são apresentados no Gráfico 2, também para o período 2007 a 2019.

\section{GRÁFICO 2 - EVOLUÇÃO DA MATRÍCULA DE EJA POR DEPENDÊNCIA ADMINISTRATIVA}

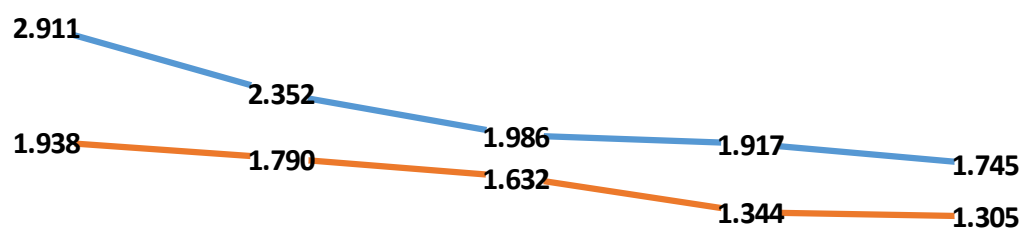

\begin{tabular}{|c|c|c|c|c|}
\hline \multicolumn{5}{|c|}{$179-157-182-207$} \\
\hline 2007 & 2010 & 2013 & 2016 & 2019 \\
\hline
\end{tabular}

Nota: Os dados da rede federal não foram incluídos em virtude de sua insignificância. Fonte: Elaboração dos autores com base no Censo Escolar do INEP a partir do LDE.

Os dados indicam uma queda de $40 \%$ na matrícula estadual, seguida de $33 \%$ nos municípios, contrapondo-se a um crescimento de $15 \%$ no setor privado. Embora minoritária, a participação privada saiu de $3,6 \%$ do total, em 2007 , para $6,3 \%$, em 2019 . A participação estadual, no mesmo período, caiu de $57,9 \%$ para $53,6 \%$, e a municipal cresceu de $38,6 \%$ para $40,1 \%$.

Quando se analisa por etapa de ensino, constata-se que, em 2019, no ensino fundamental, a participação da rede federal era desprezível; a rede estadual representava $29,9 \%$ do total; a rede municipal, $65,8 \%$, e, a privada, 4,3\%. Comparando-se com 2007, observa-se um avanço da municipalização e da rede privada, uma vez que a participação estadual era de $42,5 \%$; a municipal, $55,1 \%$, e, a privada, $2,4 \%$.

Já para o ensino médio, como esperado a oferta estadual predomina. Em 2019 a rede federal respondia por apenas $0,2 \%$ do total, a municipal por $2,2 \%$ e a privada por $9,9 \%$. Cerca da metade das matrículas privadas decorriam de convênios com o poder público (PINTO; CORREA, 2020). Na comparação com 2007, houve um avanço do setor privado sobre as demais dependências, uma vez que sua participação era de $5,7 \%$, ficando a rede estadual com $90,7 \%$; a municipal com $3,6 \%$ e a rede federal era insignificante. 
As Esperanças Perdidas da Educação de Jovens e Adultos com o Fundeb

Os dados mostram que, sempre que o setor público não atende uma etapa, o setor privado busca ocupar esse espaço, e geralmente com recursos públicos. Essa tem sido a regra no Brasil, em especial na educação infantil (PINTO; CORREA, 2020) e na formação profissional.

Ainda com relação à matrícula, uma análise específica deve ser feita sobre a presença da profissionalização na EJA, elemento fundamental para sua maior atratividade e efetividade. Como se comentou, a partir de 2009, no âmbito do Fundeb, foi criado um fator de ponderação específico para essa modalidade, embora apenas no nível médio. Pois bem, quando se compara a participação da EJA (ensino fundamental e médio) integrada à formação profissional no total de matrículas de EJA, constata-se a sua insignificância. Ela saiu de uma participação de $0,2 \%$ do total (10 mil matrículas), em 2007 , atingindo um máximo de participação, em 2012, com 2,8\% do total (109 mil matrículas), caindo para 1,6\% (53 mil matrículas) em 2019. Observa-se, assim, que as alterações nos fatores de ponderação do Fundeb pouco afetaram essa oferta, que, tudo indica, sofreu mais o efeito de programas como o Programa Nacional de Acesso ao Ensino Técnico e Emprego (Pronatec), criado em 2011 pelo governo Dilma Rousseff, com muitos recursos, em sua maioria destinados para o setor privado, e progressivamente esvaziado.

Isso fica mais claro quando se analisa o Gráfico 3, que apresenta a evolução dessa modalidade por dependência administrativa.

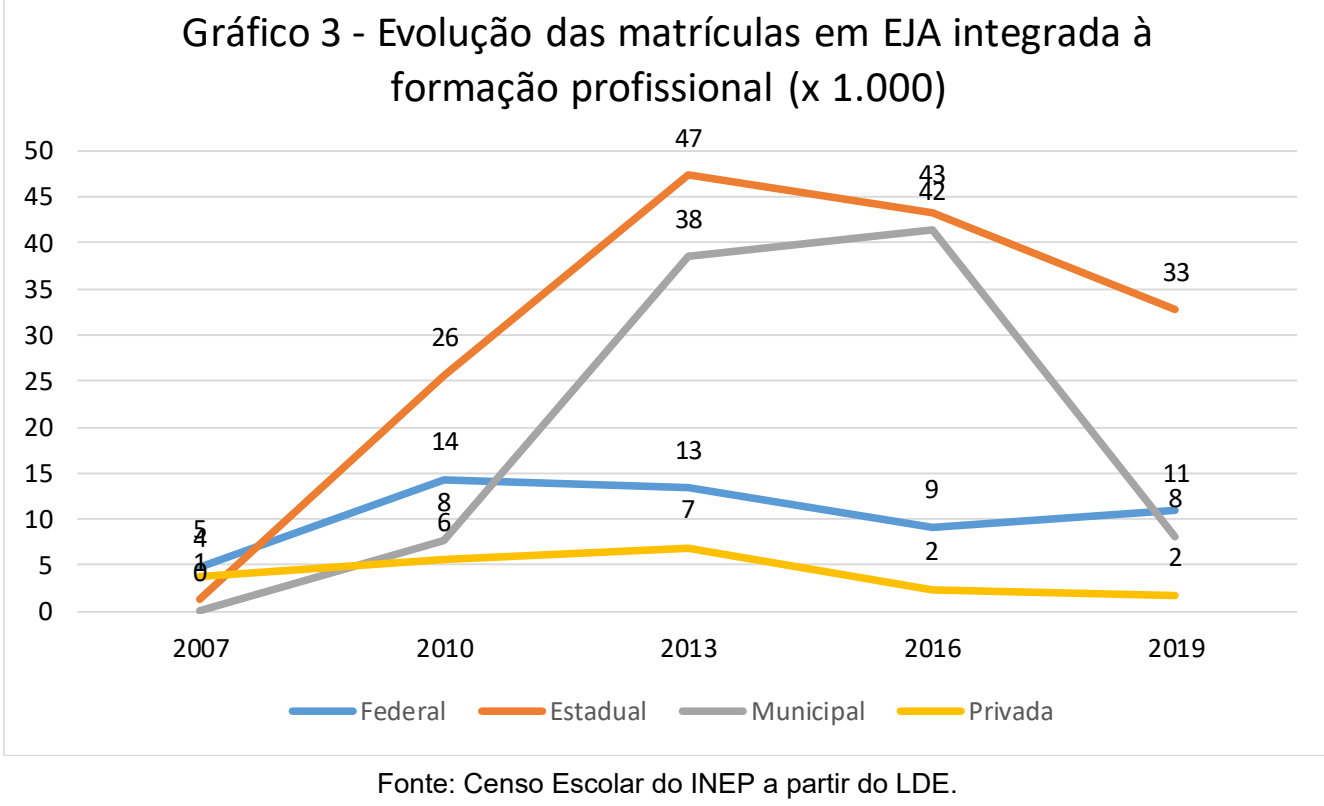

Os dados deixam bem claro a expansão e queda das matrículas das redes municipal e privada, em paralelo com a ascensão e queda do programa. De forma análoga à discussão sobre os programas Recomeço/Fazendo Escola, os dados parecem indicar que a EJA responde mais a políticas de estímulo de atendimento externas à política de fundos.

Não basta, contudo, apenas analisar o perfil e evolução das matrículas de EJA. É fundamental considerar esses dados à luz das demandas do País para o setor. Para tanto, tomar-se-á como referência o monitoramento feito pelo INEP da situação do Brasil em relação ao cumprimento das metas do PNE 2014-2024 (INEP, 2020). Neste estudo serão consideradas as metas 8, 9 e 10 do PNE 2014-2024, tendo em vista que são aquelas mais 
As Esperanças Perdidas da Educação de Jovens e Adultos com o Fundeb

diretamente associadas à EJA. A série histórica da análise será um pouco distinta da usada na análise das matrículas, pois se ajustará àquela utilizada nesta publicação.

\section{Os desafios à EJA postos no PNE 2014-2024}

Antes de iniciar a análise da evolução dos indicadores associados à EJA no Plano Nacional de Educação em vigência, cabe comentar sobre a timidez das metas que envolvem o direito à educação de jovens e adultos nesse plano. Inicia-se pela Meta 8, que estabelece: elevar a escolaridade da população de 18 a 29 anos, de modo a alcançar, no mínimo, 12 anos de estudo no último ano de vigência do Plano, para as populações do campo, da região de menor escolaridade no País e dos $25 \%$ mais pobres, e igualar a escolaridade média entre negros e não negros declarados à Fundação Instituto Brasileiro de Geografia e Estatística (IBGE). Ou seja, busca-se garantir, pelo menos, o ensino médio completo para uma faixa (18 a 29 anos) bem restrita da população, daí a timidez da meta. Segundo os indicadores, para o conjunto dessa população, essa evolução tem sido bem lenta, saindo de 10,7 anos de estudo, em 2012, para 11,6 anos, em 2019. Contudo, como se sabe, a média é uma medida ruim, particularmente em um país tão desigual como o Brasil. Os verdadeiros desafios ficam evidentes quando se analisam as regiões com os piores indicadores (Norte e Nordeste), com apenas 10,9 anos de estudo, em 2019. Apenas o Sudeste atingiu 12 anos. Na análise por estado, seis deles (Pará, Maranhão, Paraíba, Alagoas, Sergipe e Bahia) apresentam menos de 11 anos de estudo. Na comparação entre campo e cidade, a situação é crítica: 10 anos de estudo x 11,8, respectivamente, em 2019. Já na comparação entre os $25 \%$ mais pobres com os $25 \%$ mais ricos, o caráter de privilégio de classe da educação brasileira, tantas vezes denunciado por Anísio Teixeira, fica mais evidente: 9,8 anos de estudo $\times 13,5$, respectivamente, em 2019. Ou seja, para os jovens da classe média, ter 12 anos de estudo, aos 18 anos de idade, é quase natural. Por fim, para a razão entre negros e brancos, cuja meta é atingir o índice de paridade (100), o indicador era de 89,8, em 2019. Todos esses indicadores mostram que essa meta, talvez a de maior impacto do PNE para os jovens e adultos trabalhadores, mesmo considerando uma faixa etária tão reduzida (18 a 29 anos), com toda a certeza não será atingida, ainda mais no contexto das políticas recessivas dos governos Temer e Bolsonaro e da irrupção da Covid e seus efeitos sobre os segmentos mais vulneráveis da população.

Já a Meta 9 tem como objetivo elevar a taxa de alfabetização da população com 15 anos ou mais para 93,5\% até 2015 e, até o final da vigência do PNE (2024), erradicar o analfabetismo absoluto e reduzir em $50 \%$ a taxa de analfabetismo funcional. Inicialmente chama atenção a falta de ousadia da meta, em especial no que se refere à redução do analfabetismo funcional, indicador que, nos tempos atuais, é o que verdadeiramente importa. Segundo o monitoramento do INEP (INEP, 2020), em 2015, o analfabetismo absoluto atingiu $92,3 \%$, chegando a 93,4\%, em 2019, abaixo ainda da meta para 2015 e mostrando que, em 2024, ela não será cumprida. Com relação a esse indicador, os elementos de desigualdade também mostram sua força. Assim, em 2019, em quatro estados (MA, PI, PB e AL) o índice estava abaixo de $85 \%$. Para os moradores da zona rural, no mesmo ano, era de $82,9 \%$, ante $95,1 \%$ na zona urbana. Para os negros, $91,1 \%$, enquanto, para os brancos, era de 95,1 , em 2019. Finalmente, o índice era de $87,5 \%$ entre os $25 \%$ mais pobres da população com 15 anos ou mais e $97,8 \%$ entre os $25 \%$ mais ricos. Cabe lembrar que, quem reside em um 
As Esperanças Perdidas da Educação de Jovens e Adultos com o Fundeb

domicílio com um rendimento domiciliar per capita de dois salários mínimos, já se encontra entre os $25 \%$ mais ricos.

Com relação ao alfabetismo funcional, que indica se a pessoa é capaz de interpretar os textos e realizar as operações matemáticas básicas de forma integrada à sua vida, a situação é bem mais crítica. A meta para 2024 é de $9,2 \%$ de analfabetos funcionais, sendo que, entre 2012 e 2019, esse índice caiu de 18,5\% para 14,1\%, mostrando que a meta dificilmente será atingida em 2024. Em 2019, nenhuma região brasileira havia atingido a meta e no Nordeste o índice era de $23,1 \%$, sendo superior a $25 \%$ em três estados (PI, BA e AL). Na zona rural, onde escolas não param de ser fechadas, seu valor era de $31,2 \%$, ante $11,4 \%$ na zona urbana; $17,5 \%$ na população negra, frente a $9,8 \%$ na branca e $20 \%$ entre os $25 \%$ mais pobres, para $5,3 \%$ entre os $25 \%$ mais ricos. Em um país cuja mídia e a elite econômica tanto louvam o agronegócio baseado no latifúndio exportador, salta aos olhos o fato de que quase um terço da população rural com 15 anos ou mais ser composta por analfabetos funcionais. Como falar em modernidade agrícola?

Por fim, cabe analisar a situação da Meta 10, que estabelece oferecer, no mínimo, $25 \%$ das matrículas de educação de jovens e adultos, nos ensinos fundamental e médio, na forma integrada à educação profissional. Como já analisado no Gráfico 3, o cumprimento dessa meta avançou até meados da década de 2010 e depois sofreu um grande retrocesso. Segundo dados do INEP, esse índice saiu de 1,3\%, em 2010, atingindo um máximo de 3,0\%, em 2015, passando a cair desde então, chegando, em 2019, a 1,6\%, ou seja, menos de $7 \%$ da meta! Entre as regiões, em 2019, o Nordeste apresentava 0,5\%; o Sul, 0,7\%; 0,8\%, o Norte; $1,4 \%$, o Centro Oeste e, finalmente, o Sudeste com $3 \%$. Na zona rural, a taxa era de $1,1 \%$, ante $1,7 \%$ na zona urbana.

Com base nessas três metas, pode-se dizer que o Fundeb, como já mostrou o movimento das matrículas, pouco estímulo trouxe para a educação de jovens e adultos. A incapacidade da política de fundos em fomentar o cumprimento das metas do PNE, em especial na zona rural, onde a situação é mais crítica e que respondia, em 2019, por apenas $12 \%$ do total de matrículas de EJA, está associada ao fato de as escolas rurais serem de pequeno porte, sem economia de escala. Como o valor por aluno é insuficiente para cobrir esses custos, a tendência é o fechamento das escolas. Entre 2007 e 2019, foram fechadas 33.041 escolas rurais no Brasil, $77 \%$ delas nas regiões Norte e Nordeste, onde são maiores as demandas relativas às metas 8,9 e 10 do PNE, como já analisado. No Nordeste houve uma redução de $42 \%$ no número de escolas rurais.

Um outro fator que explica esse abandono do atendimento na EJA está associado ao fechamento das turmas no período noturno. Entre 2007 e 2019, foram fechadas 117 mil turmas noturnas na educação básica como um todo, queda de $40 \%$. Na EJA ensino fundamental, foram 44 mil turmas noturnas fechadas, redução também de $40 \%$. Na EJA ensino médio, houve uma expansão de 2 mil turmas, entre 2007 e 2016, sendo, contudo, essa ampliação praticamente anulada, entre 2016 e 2019, de tal forma que, no ciclo total, só foram criadas 186 turmas no período noturno em todo o Brasil. Na EJA integrada à formação profissional, entre 2007 e 2015, foram criadas 3,7 mil turmas noturnas, com uma queda para a metade do total, desde então.

A Tabela 3, a seguir, mostra, de forma ainda mais evidente, o abandono do funcionamento em período noturno por parte das escolas brasileiras. 
As Esperanças Perdidas da Educação de Jovens e Adultos com o Fundeb

Tabela 3 - Evolução do número de escolas com atendimento no período noturno por dependência administrativa

\begin{tabular}{lrrr}
\hline & 2007 & 2019 & $2019 / 2007$ \\
\hline Federal & 126 & 480 & $281 \%$ \\
Estadual & 21.044 & 15.799 & $-25 \%$ \\
Municipal & 32.538 & 16.500 & $-49 \%$ \\
Privada & 3.052 & 2.779 & $-9 \%$ \\
Total & 56.760 & 35.558 & $-37 \%$
\end{tabular}

Fonte: Elaborada por Aline Sonobe a partir dos microdados do Censo Escolar (2007; 2019).

Os dados da Tabela 3 indicam que, entre 2007 e 2019, mais de 21 mil escolas deixaram de atender no período noturno, representando uma queda de $37 \%$. Com exceção da rede federal, que quase triplicou suas matrículas, mas onde a matrícula é insignificante, todas as demais apresentaram quedas, sendo que, na rede municipal, a maior responsável por essas turmas, o atendimento caiu para a metade do número de escolas no período.

Em um processo de redução da atividade econômica e consequente queda de recursos tributários, que afeta o País desde 2015, é fácil entender por que a EJA, a modalidade mais frágil de ensino, é a rubrica mais fácil de cortar gastos. Afinal, em sua maioria, suas turmas funcionam quase que 'de favor' no período noturno das escolas estaduais e municipais, seus professores são, em geral, os mesmos que atendem o chamado ensino "regular" $\mathrm{e}$ complementam, na EJA, sua jornada com vistas a melhorar a remuneração, sem uma identidade própria como modalidade e política pública. Por fim, para muitos diretores de escola, as turmas de EJA representam uma terceira jornada de trabalho, em que faltam funcionários de limpeza, vigilância e alimentação. Em resumo, tem que cortar gastos? A EJA é o elo mais frágil. Somente a mobilização de seus estudantes pode reverter esse processo, como ocorreu, por exemplo, em São Paulo, quando os estudantes da rede estadual ocuparam escolas que o Poder Executivo pretendia fechar.

O leitor pode se perguntar por que, se as metas eram tímidas como se disse ao início deste item, elas não foram atingidas? A resposta é que, sem prioridade programática, e, principalmente, investimentos financeiros, não há como avançar nas metas do PNE, não apenas as relativas à EJA; daí se vê o mesmo plano estabelecer o comprometimento de $10 \%$ do PIB de investimentos públicos em educação pública, em sua meta 20 . Os dados do INEP indicam que o País não saiu dos $5 \%$ do PIB, mesmo com esse indicador em queda.

Finalmente, no próximo item, será feita uma discussão sobre aspectos relativos ao financiamento da EJA, um verdadeiro quebra-cabeças como se verá.

\section{O financiamento da EJA}

A análise será iniciada pelos gastos federais com a subfunção EJA (código orçamentário 366) dentro da função educação (código 12). Os dados para o período 2011 a 2021 (Projeto de Lei Orçamentária Anual) estão apresentados no Gráfico 4, em valores atualizados para 2020. Os dados de empenho (os disponíveis para a série histórica) foram obtidos no Sistema Integrado de Planejamento e Orçamento (SIOP) da Secretaria de Planejamento do Ministério da Economia ${ }^{3}$.

3 Disponível em: https://www.siop.planejamento.gov.br. Acesso em: 02 nov. 2020. 
As Esperanças Perdidas da Educação de Jovens e Adultos com o Fundeb

GRÁFICO 4 - EVOLUÇÃO DOS GASTOS FEDERAIS COM EJA (R\$ MI DE 2020)

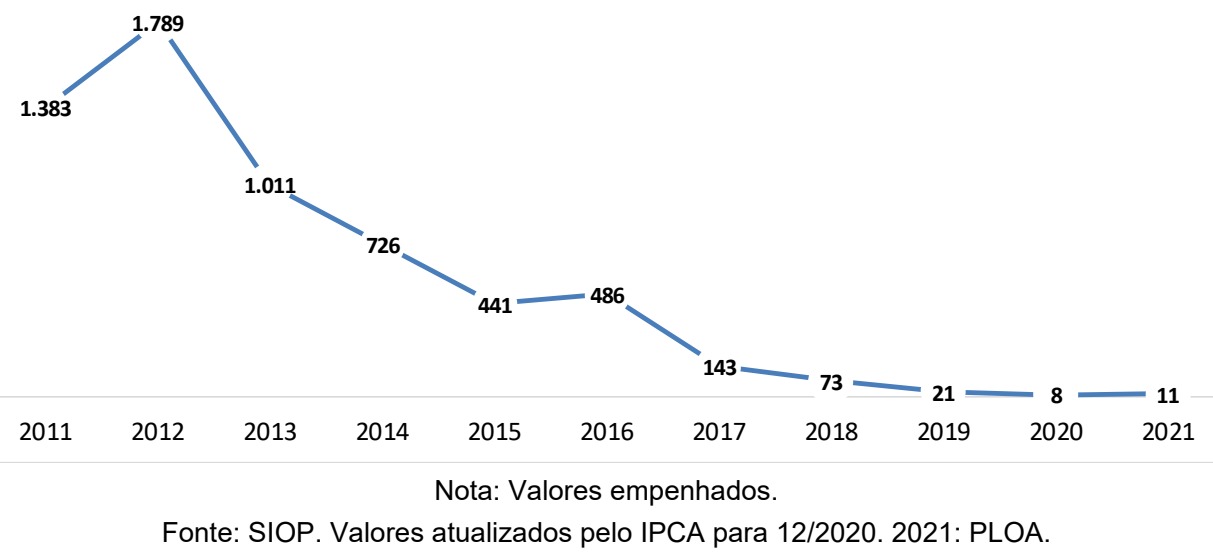

Os dados disponíveis indicam o caráter suprapartidário do desmonte das políticas federais de EJA, que atingiram seu melhor momento em 2012, no governo de Dilma Rousseff. De qualquer forma, a pá de cal foi dada nas gestões de Michel Temer e Jair Bolsonaro, de tal forma que a previsão orçamentária para 2021 no projeto enviado pelo Executivo corresponde a apenas 0,6\% do valor empenhado em 2012.

Por último, serão analisados os dados relativos aos recursos aplicados em EJA pelos estados e municípios, seus principais financiadores. E aqui os desafios metodológicos são imensos. Isso acontece porque, não obstante haja previsão de uma subfunção orçamentária específica para a EJA ( $\left.n^{\circ} 366\right)$ nos manuais de elaboração orçamentária, como já comentado, esses valores não são fidedignamente lançados nas bases de dados, seja do Sistema de Informações sobre Orçamento Público em Educação (SIOPE), seja do Sistema de Informações Contábeis e Fiscais do Setor Público Brasileiro (SICONFI). E isso acontece por uma razão relativamente simples. Como já ressaltado, as escolas que oferecem EJA, em sua maioria absoluta, assim como os professores (principal elemento de custo) que atuam nas turmas de EJA, atendem também as demais modalidades da educação básica. Destarte, todas as despesas com EJA são contabilizadas de forma agregada com as demais modalidades. Para um dimensionamento correto dos gastos efetivos em EJA, as secretarias de educação teriam que discriminar em suas folhas de pagamento a carga efetiva dos docentes com as turmas de EJA, bem como ponderar de forma proporcional à matrícula, por exemplo, as despesas que envolvem os demais profissionais da educação (direção, coordenação pedagógica, limpeza, manutenção, alimentação, vigilância etc.), além das outras despesas de custeio e capital. Isso simplesmente não é feito. Espera-se que, com as determinações do Novo Fundeb, ocorra um avanço nesse sentido. Entende-se também que não é adequado considerar para ponderação dos gastos com EJA as matrículas registradas no Fundeb tendo como baliza os respectivos fatores de ponderação previstos para a EJA, ou seja, aplicando um redutor, uma vez que não há exigência de que os recursos destinados no âmbito do Fundeb para cada etapa ou modalidade corresponda à sua participação no cômputo das matrículas. Ou seja, o dinheiro do fundo não é carimbado para cada etapa ou modalidade de ensino. Ademais, os recursos destinados à educação básica vão além daqueles que compõem o fundo. Entende-se como positiva essa determinação legal, por não engessar demais o orçamento e principalmente por abrir a possibilidade de um gasto superior 
As Esperanças Perdidas da Educação de Jovens e Adultos com o Fundeb

nas modalidades em que os fatores de ponderação são claramente inferiores aos custos reais, como é o caso das creches e da EJA.

Dessa forma, para efeito deste trabalho, entende-se que a melhor aproximação para se obter o quanto estados e municípios destinam ao atendimento de EJA seja considerar que essa participação da modalidade no financiamento seja proporcional àquela existente na matrícula. É fato que pode ocorrer aí um risco de superestimar esses gastos, uma vez que as turmas de EJA funcionam geralmente à noite (92\%, em 2019), quando é menor o número de funcionários de suporte pedagógico e de apoio operacional; muitas vezes sem alimentação e com salas de leitura fechadas. Há também o fato de os custos em creche serem sabidamente mais elevados, em função da menor razão de alunos por turma e do predomínio da jornada em tempo integral. Por outro lado, o elemento de maior impacto no custo é a remuneração dos professores e, como já se comentou, no caso do ensino fundamental, a razão alunos/turma é menor na EJA, o que implica em maior valor por aluno quando comparado às turmas que não são de EJA nessa etapa. Já no caso do ensino médio, a razão de alunos/turma na EJA é equivalente àquela da modalidade chamada de regular. É importante afirmar de toda forma que o valor ao qual se chegará trata-se de uma primeira aproximação, mas que com certeza é bem mais próximo da realidade do que a utilização de valores declarados em bases como o SIOPE, por exemplo.

O Gráfico 5, a seguir, traz a participação das matrículas de EJA no conjunto das matrículas públicas da educação básica, por unidade federada, considerando a média de 2015 a 2019.

Gráfico 5- Participação da matrícula de EJA na matrícula da educação básica pública - (2015-2019)

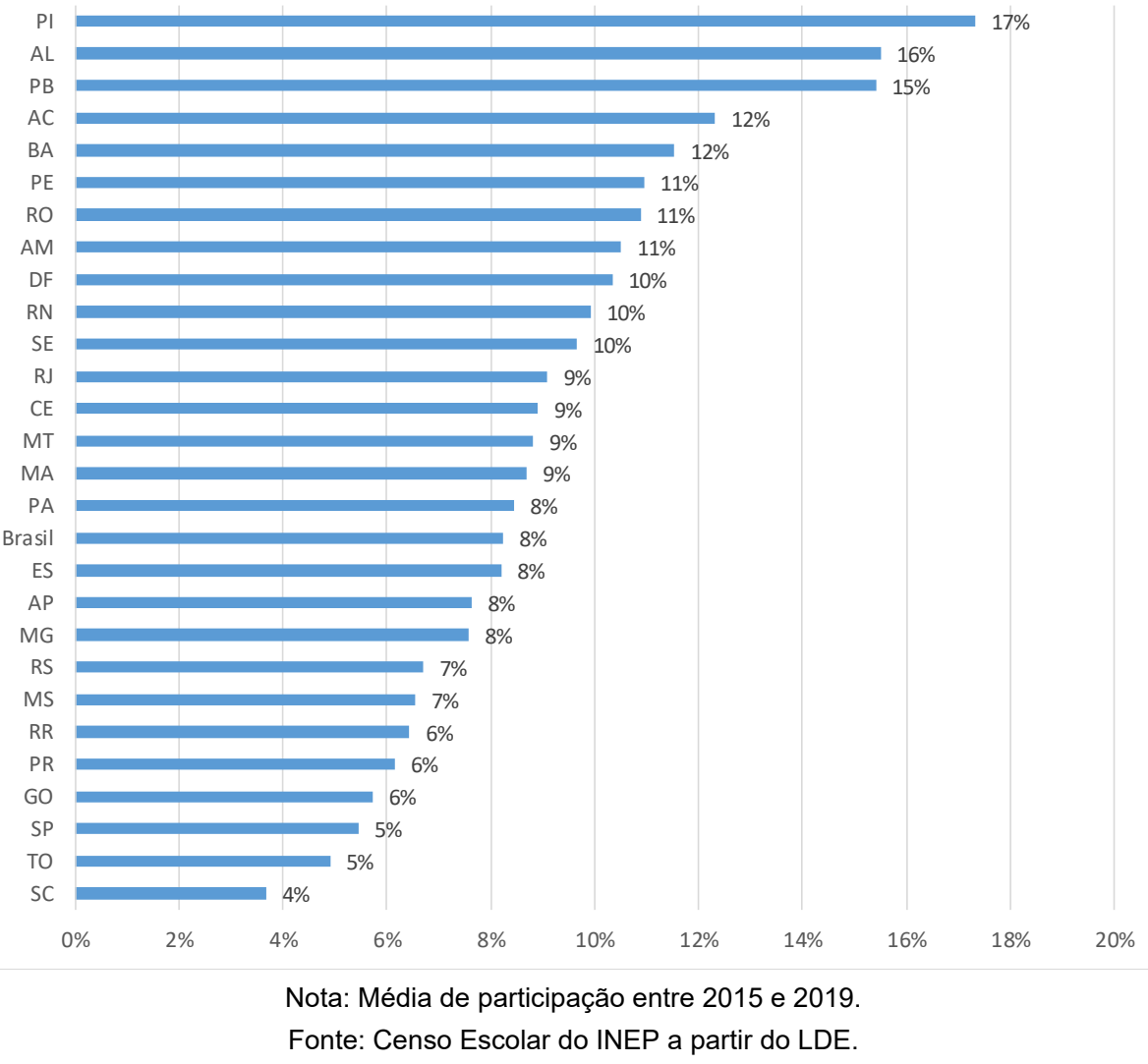


As Esperanças Perdidas da Educação de Jovens e Adultos com o Fundeb

Como se discutiu no início, desde a criação do Fundef, houve por parte do Executivo federal um temor pela explosão das matrículas de EJA com a política de fundos. No caso do Fundef, esse temor se revelou com o veto às matrículas nessa modalidade e, com o Fundeb, no limite de destinação de $15 \%$ dos recursos do fundo. Os dados mostram como foi equivocada essa postura. Na média do País, mesmo com a matrícula total da educação básica em queda, a participação de EJA na rede pública ficou em apenas $8 \%$ do total, entre 20015 e 2019. Ainda com relação ao Gráfico 5, constata-se que, apenas oito estados (AM, RO, PE, $\mathrm{BA}, \mathrm{AC}, \mathrm{PB}, \mathrm{AL}$ e PI), das regiões Norte e Nordeste, apresentaram taxas de participação de EJA acima de $10 \%$. O dado positivo é que exatamente nessas regiões as demandas da EJA são maiores, como analisado no item sobre a EJA no PNE.

Já o Gráfico 6 apresenta a evolução da participação de EJA na matrícula total da educação básica pública entre 2007 e 2019.

GRÁFICO 6 - EVOLUÇÃO DA PARTICIPAÇÃO DA EJA NA MATRÍCULA DA EDUCAÇÃO BÁSICA PÚBLICA

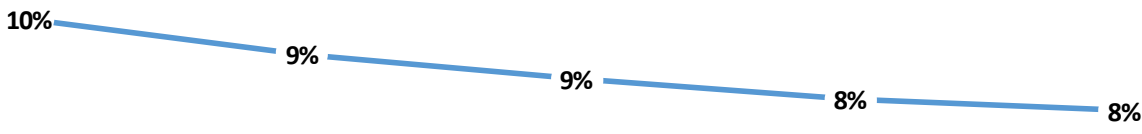

\begin{tabular}{lccc}
2007 & 2010 & 2013 & 2016 \\
\hline \multicolumn{3}{c}{ Fonte: Elaboração dos autores. }
\end{tabular}

Observa-se assim, de forma inconteste, como o Fundeb não conseguiu influenciar positivamente no atendimento de EJA, com uma queda de $20 \%$ na participação (dois pontos percentuais), mesmo em um período no qual a matrícula total da educação básica pública foi reduzida em 8 milhões de estudantes (queda de 17\%).

Finalmente, a Tabela 4, feita com base nos dados preliminares do Simulador de Custo Aluno Qualidade (SIMCAQ), elaborado pela equipe do Laboratório de Dados Educacionais (LDE) da Universidade Federal do Paraná, traz uma estimativa dos recursos envolvidos no financiamento da EJA. É importante esclarecer que se trata de um sistema ainda em consolidação e que busca integrar, com base nos dados do SIOPE e SICONFI, o conjunto de recursos destinados à educação pelos entes federados. As estimativas do potencial mínimo de recursos destinados à educação mostradas a seguir já foram elaboradas levando em conta o conceito de Valor Anual Total por Aluno (VAAT) do novo Fundeb, aprovado em 2020, e consideram: 
Receita Potencial mínima vinculada para a educação básica (RPEb) =

$25 \%$ da Receita Líquida de Impostos próprios

- (menos) receitas destinadas ao Fundeb

+ (mais) receitas recebidas do Fundeb

+ (mais) Salário Educação (cota municipal/Estadual)

+ (mais) complementação atual da União ao Fundeb

+ (mais) receitas de programas (PNAE+PNATE+PPDE)

- (menos) despesas com educação superior.

Dadas as enormes dificuldades de obtenção dos gastos efetivos em educação, em especial dos 5.570 municípios brasileiros, e mesmo de alguns estados que não detalham seus dados no SIOPE (como é o caso do Rio Grande do Sul), a opção pela receita potencial mínima, no momento, propicia a estimativa mais fidedigna dos valores envolvidos na educação básica.

A Tabela 4 apresenta os valores da receita potencial mínima estimada para a educação básica de cada UF, assim como os valores estimados para EJA, considerando a sua participação na matrícula total e a estimativa de recursos disponíveis por aluno da educação básica para o ano de 2019.

Tabela 4 - Receita potencial mínima de recursos para educação Básica, EJA e valor disponível por aluno - 2019

\begin{tabular}{|c|c|c|c|c|}
\hline & $\begin{array}{l}\text { Receita Educação Básica } \\
\qquad \$ \text { bi }\end{array}$ & Receita EJA* & $\begin{array}{r}\text { Valor por aluno-an } \\
\text { Bá }\end{array}$ & $\begin{array}{l}\text { o (R\$) na Educação } \\
\text { sica }\end{array}$ \\
\hline & & $\mathrm{R} \$ \mathrm{mi}$ & Rede estadual & Redes municipais** \\
\hline $\mathrm{AC}$ & 1,7 & 170 & 6.354 & 4.411 \\
\hline $\mathrm{AL}$ & 3,2 & 539 & 7.137 & 4.067 \\
\hline AM & 5,9 & 587 & 5.398 & 4.203 \\
\hline $\mathrm{AP}$ & 1,5 & 99 & 7.381 & 5.121 \\
\hline $\mathrm{BA}$ & 17,2 & 1.962 & 6.292 & 4.431 \\
\hline $\mathrm{CE}$ & 10,2 & 918 & 6.936 & 4.358 \\
\hline DF & 4,1 & 410 & 8.023 & - \\
\hline ES & 4,4 & 352 & 7.178 & 5.246 \\
\hline $\mathrm{GO}$ & 8,6 & 487 & 6.975 & 6.559 \\
\hline MA & 9,3 & 847 & 6.460 & 4.037 \\
\hline MG & 25,1 & 1.506 & 5.590 & 6.005 \\
\hline MS & 4,5 & 230 & 6.968 & 6.590 \\
\hline MT & 5,7 & 456 & 7.146 & 6.662 \\
\hline PA & 10,9 & 712 & 5.823 & 4.156 \\
\hline$\overline{P B}$ & 4,6 & 668 & 6.111 & 4.706 \\
\hline PE & 10,4 & 1.144 & 6.411 & 4.533 \\
\hline $\mathrm{Pl}$ & 4,4 & 748 & 5.950 & 4.330 \\
\hline PR & 15,5 & 1.085 & 6.020 & 6.362 \\
\hline RJ & 19,1 & 1.871 & 8.758 & 5.554 \\
\hline $\mathrm{RN}$ & 4 & 240 & 6.749 & 4.906 \\
\hline RO & 2,6 & 245 & 6.640 & 5.471 \\
\hline
\end{tabular}


As Esperanças Perdidas da Educação de Jovens e Adultos com o Fundeb

\begin{tabular}{|c|c|c|c|c|}
\hline RR & 1,3 & 117 & 9.545 & 6.070 \\
\hline $\mathrm{RS}$ & 15,8 & 857 & 6.989 & 8.005 \\
\hline SC & 10,6 & 363 & 7.206 & 7.105 \\
\hline SE & 3 & 306 & 7.852 & 5.253 \\
\hline $\mathrm{SP}$ & 70,7 & 3.722 & 6.880 & 7.333 \\
\hline TO & 2,8 & 124 & 7.771 & 5.954 \\
\hline Brasil & 277 & 20.764 & 6.936 & 5.949 \\
\hline
\end{tabular}

Os dados obtidos no âmbito do LDE indicam um potencial de 277 bilhões de reais para a educação básica no ano de 2019, o que corresponde a 3,7\% do PIB. Como comparação, é importante dizer que os recursos do Fundeb correspondiam, no mesmo ano, a 2,3\% do PIB, ou seja, $62 \%$ desse total. Tendo como parâmetro sua participação nas matrículas, a EJA teria recursos de cerca de $\mathrm{R} \$ 21$ bilhões, cerca de $7,5 \%$ do total. Em termos do PIB, corresponderia a $0,28 \%$.

A Tabela 4 apresenta também uma estimativa de valor médio disponível por aluno para cada UF, considerando as respectivas redes estaduais e municipais. No caso das últimas optou-se pela mediana. Nunca é demais lembrar que são valores médios e não consideram diferenças entre cada etapa ou modalidade, mas, pelo que já se argumentou até agora, podese afirmar que é uma boa aproximação para o gasto por aluno em turmas de EJA presencial nas redes públicas. Observa-se que as redes estaduais apresentam um potencial médio de recursos por aluno 17\% acima das redes municipais. Essa distância já foi muito maior e sua redução pode ser atribuída à política de fundos. Em apenas quatro estados as redes municipais apresentam uma situação melhor que a rede estadual: Rio Grande do Sul, São Paulo, Minas Gerais e Paraná, que representam regiões onde o processo de municipalização foi menos intenso no período dos fundos. Já em estados do Nordeste, onde boa parte das matrículas do ensino fundamental encontra-se com os municípios, a situação é inversa. Assim, em estados como Alagoas, Maranhão e Ceará, metade dos municípios apresentam uma disponibilidade de recursos por aluno que é inferior a um terço daqueles à disposição da rede estadual. Isso acontece também com Roraima e Rio de Janeiro, outro ente bastante municipalizado, desde que o então estado da Guanabara foi extinto. Em dez estados (MA, AL, PA, AM, PI, CE, BA, PE e PB) a mediana dos municípios é inferior a $R \$ 400$ por mês, um valor que corresponde a um terço das mensalidades das escolas privadas de classe média do País. Isso mostra mais uma vez os limites de toda a engenharia criada para o financiamento da educação no Brasil: avançou-se na redução das desigualdades mais significativas, mas o valor por aluno ainda é muito baixo e ainda existem diferenças significativas, em especial entre os municípios (ALVES; PINTO, 2020).

\section{Considerações finais}

Os dados apresentados neste trabalho mostram que, ao contrário das expectativas otimistas, o Fundeb não representou um alento para a Educação de Jovens e Adultos, reforçando o que alguns estudos de caráter mais localizado já apontavam (DI PERRO, 2014) e reforçando o caráter excludente de nossas políticas educacionais para a área (RUMMERT; VENTURA, 2008). 
As Esperanças Perdidas da Educação de Jovens e Adultos com o Fundeb

De uma maneira geral, essa constatação se baseia nos seguintes indicadores:

- Queda na matrícula de EJA no ensino fundamental e médio;

- Queda nas matrículas de EJA integrada à formação profissional;

- Queda da participação da EJA no total das matrículas na educação básica, mesmo em um cenário de queda dessa última;

- Avanço extremamente lento em relação às metas do PNE mais diretamente relacionadas à EJA, indicando o seu provável não atingimento em 2024.

Particularmente em relação a seu financiamento, constatou-se:

- Queda dos gastos federais empenhados, a partir de 2012, com o abandono do setor, a partir de 2017, nos governos Temer e Bolsonaro;

- o pouco que resta de atendimento está na mão dos estados (54\%) e municípios (40\%), mas, entre 2007 e 2019, houve uma queda de 7,5\% na participação estadual, mal compensada por uma elevação de apenas $4 \%$ na presença municipal;

- com isso, embora pequena, a participação do setor privado cresceu $75 \%$ no período, em parte, com o recebimento de repasses de recursos públicos;

- um potencial de recursos com o atendimento na EJA presencial de $0,28 \%$ do PIB, cerca de $7,5 \%$ do potencial estimado de recursos para a educação básica.

Os dados apontam também que, por funcionar, em geral, no período noturno, as turmas de EJA foram duramente atingidas com as políticas de fechamento das escolas no período noturno. Nunca é demais ressaltar que, objetivamente, as turmas de EJA funcionam como se fossem uma liberalidade das escolas que as abrigam, e não como um direito.

Esse fechamento está associado à redução das turmas denominadas "regulares" dos anos finais do ensino fundamental e do ensino médio que funcionavam à noite, em função dos programas de correção de fluxo e melhoria da taxa líquida de matrícula que levou à redução da idade média dos alunos. Nunca é demais lembrar que, abrir a escola em três turnos, significa trabalho extra para a equipe de direção e sobrecarga para os funcionários de apoio, em um contexto de corte de pessoal por redes estaduais e municipais. Por isso, não é exagero dizer que muito diretores ficam aliviados ao não terem que abrir as escolas das quais são responsáveis no período noturno.

Por tudo isso, e em face a uma queda dos recursos tributários desde $2015 \mathrm{com}$ as políticas recessivas, a saída adotada por muitos governantes estaduais e municipais, estes últimos assoberbados com a municipalização do ensino fundamental desde o Fundef e com as pressões pela ampliação da oferta da educação infantil, foi reduzir drasticamente o atendimento em EJA, particularmente no ensino fundamental. Isso em um contexto em que as metas definidas pelo atual PNE, e pelo anterior, apontam para a necessidade imperiosa de incremento nas políticas para o setor.

Como enfrentar essa questão? Basta aproximar o fator de ponderação de EJA no Fundeb do seu custo real e assegurar que o recurso destinado à EJA corresponda a seu peso na matrícula da educação básica? Entende-se que não. Como já aqui ponderado, não há elementos para dizer que os recursos destinados aos alunos de EJA por estados e municípios sejam muito diferentes daqueles destinados a seus colegas do chamado ensino "regular", uma vez que os professores, as escolas e a razão alunos/turma são equivalentes. 
Infelizmente, o problema é mais grave. No início da política de fundos, com o Fundef, criouse a impressão (ante os dados iniciais de matrícula) de que a política de fundos estimularia a 'busca pelo aluno', uma vez que, quanto mais alunos, mais recursos. Na verdade, trata-se de uma falácia, pois, no âmbito de cada ente federado, o recurso total só depende da receita da cesta de impostos que compõe o fundo. A matrícula, na verdade, só afeta a divisão de recursos entre o governo estadual e respectivos municípios, sem alterar a receita total. $\mathrm{O}$ mesmo vale para a complementação federal no Fundeb, que também não está associada à matricula (como ocorria na fórmula do CAQ no Fundef, nunca cumprida), mas tão somente ao aporte de recursos dos demais entes. Portanto, mais alunos, no âmbito de cada ente, não significa mais recursos, mas um menor valor per capita. Foi isso o que, realisticamente, descobriram prefeitos e governadores e isso o que explica o pequeno esforço de ampliação do atendimento, quando não sua redução, sobretudo em um contexto de queda dos recursos vinculados.

E o novo Fundeb traz esperanças? Não, da forma como está regulamentado até o momento, que, em linhas gerais, segue a lógica de seu antecessor. Uma brecha que poderia ser utilizada em favor das políticas da EJA seria a chamada complementação $\operatorname{VAAR}^{4}$ de $2,5 \%$ da contribuição de estados, DF e municípios ao fundo, por parte da União (art. $5^{\circ}$, inc. III da lei $\left.n^{\circ} 14.113 / 2020\right)$. Essa novidade é fruto da pressão dos setores ligados ao mercado, que dizem que o recurso federal deve estar associado aos 'resultados' dos estudantes em testes padronizados, daí o "R" da sigla, e que não existe no texto constitucional (art. 212-A). Contudo o texto aprovado é mais rico e complexo do que gostariam aqueles que se balizam pela batuta do mercado, como o Insper, a Fundação Lemann e o Todos pela Educação. A norma, na verdade, estabelece que essa complementação será destinada a "[...] redes públicas que, cumpridas condicionalidades de melhoria de gestão, alcançarem evolução de indicadores a serem definidos, de atendimento e de melhoria da aprendizagem com redução das desigualdades, nos termos do sistema nacional de avaliação da educação básica" (grifo nosso). O ponto que se levanta aqui é o seguinte: como se falar em melhoria da aprendizagem com redução das desigualdades quando não existe atendimento? A tese defendida é que, inicialmente, essa complementação deve estar integralmente vinculada a programas de expansão de matrículas na educação básica, em consonância com as metas do PNE, para, a partir de então, discutir as metas de aprendizado vinculadas à redução das desigualdades, sempre em consonância com o sistema nacional de avaliação da educação básica, que sequer existe. Essa interpretação do VAAR, com certeza, é polêmica, e, de toda forma, essa complementação se inicia (com um índice de 0,75\%) apenas em 2023, e atinge sua plenitude em 2026.

No âmbito do novo Fundeb a única maneira de estimular a expansão do atendimento será com a regulamentação do CAQ. É fundamental a política de fundos sair da lógica do 'recurso disponível' para aquela do 'recurso necessário' para se garantir um padrão mínimo de qualidade de ensino, como estabelece a Constituição Federal em seu art. $211, \S 1^{\circ}$ desde 1996. Somente quando os valores de cada etapa e modalidade do Fundeb tiverem como referência um custo real por aluno que garanta condições adequadas de qualidade do ensino

4 Cabe comentar que essa sigla não consta na EC 108/2019 que criou o novo Fundeb, mas apenas na lei $n^{\circ}$ 14.113/2020 que o regulamenta, sem que esta explicite o seu significado. $O$ anexo da lei (item 2.b) usa a expressão "recursos por resultados (VAAR)". 
As Esperanças Perdidas da Educação de Jovens e Adultos com o Fundeb

(o CAQ), cabendo ao governo federal complementar os recursos para estados e municípios onde esse valor não for assegurado, os entes federados serão estimulados à busca ativa de alunos nas diferentes etapas e modalidades, pois saberão que não pagarão a conta sozinhos. Enquanto isso não ocorre, a medida emergencial para a EJA seria resgatar o mecanismo do programa Recomeço/Fazendo Escola, de modo que o governo federal destine diretamente recursos por aluno para estados e municípios com base na matrícula na modalidade. Essa questão é particularmente urgente, considerando as metas do PNE, em especial na EJA do campo e na integração com a educação profissional.

\section{Referências}

ALVES, Thiago; PINTO, José Marcelino de Rezende. As Múltiplas Realidades Educacionais dos Municípios no Contexto do Fundeb. Fineduca - Revista de Financiamento em Educação, v. 10, p. 1-23, 2020.

BORGES, Irlanda Aglae; JESUS, Wellington F. Financiamento da educação na EJA: contexto e desafio. In: CONGRESSO NACIONAL DE EDUCAÇÃO - EDUCERE, 11., 2013, Curitiba. Anais [...] Curitiba: PUC-PR, 2013. p. 1-13.

BRASIL. Constituição da República Federativa do Brasil. Diário Oficial da União, Brasília, 1988.

BRASIL. Lei 9.424. Dispõe sobre o Fundo de Manutenção e Desenvolvimento do Ensino Fundamental e de Valorização do Magistério, na forma prevista no art. $60, \S 7^{\circ}$, do Ato das Disposições Constitucionais Transitórias, e dá outras providências. Diário Oficial da União, Brasília, 24 dez. 1996.

BRASIL. Lei 11.494. Regulamenta o Fundo de Manutenção e Desenvolvimento da Educação Básica e de Valorização dos Profissionais da Educação - FUNDEB, de que trata o art. 60 do Ato das Disposições Constitucionais Transitórias e dá outras providências. Diário Oficial da União, Brasília, 20 jun. 2007.

BRASIL. Ministério da Educação. Documento base nacional preparatório à VI CONFINTEA. Brasília: Secretaria de Educação Continuada, Alfabetização e Diversidade, mar. 2008.

BRASIL. Lei 14.113. Regulamenta o Fundo de Manutenção e Desenvolvimento da Educação Básica e de Valorização dos Profissionais da Educação (Fundeb), de que trata o art. 212-A da Constituição Federal; revoga dispositivos da Lei $n^{\circ}$ 11.494, de 20 de junho de 2007; e dá outras providências. Diário Oficial da União, Brasília, 25 dez. 2020.

CAMPANHA Nacional pelo Direito à Educação. CAQi e o CAQ no PNE. Quanto custa a educação pública de qualidade no Brasil. São Paulo: Campanha Nacional pelo Direito à Educação, 2018.

CARREIRA, Denise; PINTO, José Marcelino de Rezende. Custo aluno-qualidade inicial: rumo à educação pública de qualidade no Brasil. São Paulo: Global, 2007. v. 1. 127p.

DI PIERRO, Maria Clara. O impacto da inclusão da Educação de Jovens e Adultos no Fundo de Manutenção e Desenvolvimento da Educação Básica (FUNDEB) no estado de São Paulo. In: CATELLI JR., Roberto; HADDAD, Sergio; RIBEIRO, Vera Masagão (Org.). A EJA em 
As Esperanças Perdidas da Educação de Jovens e Adultos com o Fundeb

Xeque: Desafios das políticas de Educação de Jovens e Adultos no século XXI. São Paulo: Global Editora, 2014. p. 39-76.

INEP. Instituto Nacional de Estudos e Pesquisas Educacionais Anísio Teixeira. Relatório do $3^{\circ}$ ciclo de monitoramento das metas do Plano Nacional de Educação - 2020. Brasília: INEP, 2020.

LDE. Laboratório de Dados Educacionais da Universidade Federal do Paraná. Dados. Curitiba, 2020. Disponível em: https://dadoseducacionais.c3sl.ufpr.br/\#/. Acesso em: 02 jun. 2020.

PINTO, José Marcelino de Rezende. Financiamento da educação no Brasil: um balanço do governo FHC (1995-2002). Educação e Sociedade, Campinas, v. 23, n. 80, p. 109-136, 2002.

PINTO, José Marcelino de Rezende. O Financiamento da Educação na Constituição Federal De 1988: 30 anos de mobilização social. Educação e Sociedade, v. 39, p. 1-24, 2018.

PINTO, José Marcelino de Rezende; CORREA, Bianca Cristina. Educação infantil e a política de fundos: como tem caminhado essa etapa educacional, em especial com a aprovação do Fundeb? Fineduca - Revista de Financiamento em Educação, v. 10, p. 1-26, 2020.

RUMMERT, Sonia Maria; VENTURA, Jaqueline Pereira. Políticas públicas para educação de jovens e adultos no Brasil: a permanente (re)construção da subalternidade: considerações sobre os Programas Brasil Alfabetizado e Fazendo Escola. Educar, Curitiba, n. 29, p. 29-45, 2007.

José Marcelino de Rezende Pinto é mestre e doutor em Educação pela Universidade Estadual de Campinas (1989 e 1994). Atualmente é professor titular da Universidade de São Paulo. Tem experiência na área de Política e Gestão Educacional, com ênfase em financiamento da Educação, municipalização do ensino, regime federativo e educação do campo.

ORCID: http://orcid.org/0000-0001-8355-2561

E-mail: jmrpinto@ffclrp.usp.br 


\section{Editores do volume 11}

Márcia Aparecida Jacomini - Universidade Federal de São Paulo, Brasil

José Marcelino de Rezende Pinto - Universidade de São Paulo, Brasil

\section{Comitê Editorial}

Nalú Farenzena - Universidade Federal do Rio Grande do Sul, Brasil

Juca Gil - Universidade Federal do Rio Grande do Sul, Brasil

Theresa Adrião - Universidade Estadual de Campinas, Brasil

Ângelo Ricardo de Souza - Universidade Federal do Paraná, Brasil

\section{Conselho Editorial}

\section{Alejandro Morduchowicz}

Universidad Pedagógica, Provincia de Buenos Aires, Argentina

Andréa Barbosa Gouveia

Universidade Federal do Paraná, Brasil

Fernanda Saforcada

Universidade de Buenos Aires, Argentina

Jacques Velloso

Universidade de Brasília, Brasil

João Monlevade

Senado Federal, Brasil

Jorge Abrahão de Castro

Instituto de Pesquisa Econômica Aplicada / IPEA, Brasil

Lisete Regina Gomes Arelaro

Universidade de São Paulo, Brasil

Luis Carlos Sales

Universidade Federal do Piauí, Brasil

Luiz de Sousa Junior

Universidade Federal da Paraíba, Brasil

Luiz Fernandes Dourado

Universidade Federal de Goiás, Brasil

Magna França

Universidade Federal do Rio Grande do Norte, Brasil

Marcos Edgar Bassi

Universidade Federal de Santa Catarina, Brasil

Maria Angélica Pedra Minhoto

Universidade Federal de São Paulo, Brasil

Maria Beatriz Luce

Universidade Federal do Rio Grande do Sul, Brasil

Maria Dilnéia Espíndola Fernandes

Universidade Federal de Mato Grosso do Sul, Brasil

Nelson Cardoso do Amaral

Universidade Federal de Goiás, Brasil

Nicholas Davies

Universidade Federal Fluminense, Brasil

Robert E. Verhine

Universidade Federal da Bahia, Brasil

Romualdo Portela de Oliveira

Universidade de São Paulo, Brasil

Rosana Gemaque Rolim

Universidade Federal do Pará, Brasil

Rubens Barbosa de Camargo

Universidade de São Paulo, Brasil

Theresa Adrião

Universidade Estadual de Campinas, Brasil

Tristan McCowan

University of London, Reino Unido

Vera Jacob

Universidade Federal do Pará, Brasil

Vera Peroni

Universidade Federal do Rio Grande do Sul, Brasil

Vitor Henrique Paro

Universidade de São Paulo, Brasil

\section{Equipe editorial}

Apoio ao Comitê Editorial: Caio Cabral da Silva

Diagramação, Revisão de português e normalização: Edson Leonel de Oliveira

Revisão de inglês: Sabrina Ferreira

Fineduca - Revista de Financiamento da Educação

Associação Nacional de Pesquisa em

Financiamento da Educação

e-mail: revista.fineduca@gmail.com | site: http://seer.ufrgs.br/fineduca 